\title{
Adherence to Antiepileptic Drugs and Seizure Control Among Patients with Epilepsy
}

\author{
Somen Chowdhury ${ }^{1 *}$ \\ Ashok Kumar Phani \\ Priyatosh Das ${ }^{3}$ \\ Zaman Ahammed ${ }^{4}$ \\ Pradip Kumar Kayasthagir ${ }^{4}$ \\ Md Hassanuzzaman ${ }^{4}$
}

\begin{abstract}
Background: Anti-Epileptic Drugs (AEDs) are the primary therapeutic modes for epileptic patients and have been demonstrated to control seizure, which decreases morbidity and mortality associated with epilepsy. There is a paucity of data on drug adherence and seizure control status among epileptic patients in Bangladesh. The aim of this study was therefore to assess adherence among epileptic patients and to see association between adherence and control of seizures.
\end{abstract}

Methods and materials: A cross-sectional observational study was conducted among 253 patients who visited into outdoor and admitted inindoor of Neurology and Medicine Department of Chattogram Medical College Hospital (CMCH) with a clinical diagnosis of epilepsy. Epileptic Patients who had taken AED for at least one year or more were recruited in the study to evaluate adherence and seizure control through patient interview. Factors affecting adherence were determined using regression analysis.

Results: $38.8 \%$ patients were adherent to their treatment and only $33.6 \%$ of the patients had controlled seizure, forgetfulness (35\%) was the most reason for nonadherence. Monontherapy was commonly (72.7\%) used, among which Valproic acid was the most commonly utilized (30.4\%) single anticonvulsant drug. Many factors were affecting patient's adherence such as socio-demographic related factors (age, education, occupation), therapy related factors and cost. Adherence to AED was found to have a significant association with seizure control status.

Conclusions: The rate of adherence observed in this study was low. The most common reason for nonadherence was forgetfulness. The findings indicate that adherence was associated with well seizure control.

Key words: Epilepsy; Seizure; Non adherence; AED (Anti-Epileptic Drugs).

\section{INTRODUCTION}

In 2014, the International League Against Epilepsy (ILAE) revised the definition of epilepsy 'as a disease of the brain defined by any of the following conditions:

i) At least two unprovoked (or reflex) seizures occurring $>24 \mathrm{~h}$ apart

${ }^{*}$ Correspondence to:

Dr. Somen Chowdhury

Jr. Consultant

Department of Neurology

Chattogram Maa-O-Shishu General Hospital

Chattogram, Bangladesh.

Mobile : +8801711197674

Email: drsomen9@gmail.com

Date of Submission : 10.11 .2019

Date of Acceptance ： 20.12 .2019

www.banglajol.info/index.php/CMOSHMCJ ii) One unprovoked (or reflex) seizure and a probability of further seizures similar to the general recurrence risk (At least 60\%) after two unprovoked seizures, occurring ever the next 10 years

iii) Diagnosis of an epilepsy syndrome ${ }^{1}$.

About $10 \%$ of the whole world population living a normal life span can expect to have at least one epileptic seizure. At least 50 million will have recurrent seizures. This could be underestimated; as partial seizures are often not recognized as such in the developing world. Out of the 50 million, 40 million receive no treatment when $70 \%$ of these could lead seizure-free lives ${ }^{2}$. 
WHO estimates that there are at least 1.5-2.0 million people with epilepsy in Bangladesh ${ }^{3}$. About half of the total epilepsy population lives in $\mathrm{Asia}^{4}$. Incidence as well as prevalence of epilepsy is generally lower in developed regions in comparison to developing region poses a huge social and economic burden to the poor ${ }^{5.6}$.

The mainstay of treatment for epilepsy remains symptomatic despite the rapid expansion in knowledge of its neurological disabilities. The management of epilepsy includes pharmacological, non- pharmacological (Vagal nerve stimulation \& ketogenic diet) and surgical (Lobectomy and lesionectomy are among several possible curative surgeries) approaches. The principle of epilepsy management should be individualized and the selection of treatments should aim to control symptoms as well as to prevent other complications. There are a number of drugs available for treatment of epilepsy in modern therapy.

The goal in treating patients with epilepsy is a cost-effective approach to control of seizure or a reduction in their number and frequency while avoiding drug interactions and side effects, so as to achieve the best possible quality of life. In an individual with epilepsy adherence to medication is crucial in preventing or minimizing seizure and there is cumulative impact on everyday life. Non-adherence to AEDs can results in break through seizure and has been associated with excess urgent clinic visit and hospitalization.

So it is important to know the drug adherence among patient with epilepsy. In order to address the issue of adherence in low resource setting, the rate and determinants of factor of adherence should be established. Understanding these factors can enable a prescriber to promote adherence when working with susceptible patients and can also encourage the development of interventions to improve adherence. Moreover, it can provide a cost effective approach which is one of the most important factor in our setting by not changing medications or increasing dose without confirming adherence.

\section{METHODS AND MATERIALS}

A cross sectional observational study was done among 253 clinically diagnosed epileptic patients in the Neurology and Medicine department of Chattogram Medical College Hospital $(\mathrm{CMCH})$ from 01.03.2016 to 31.12.2016. Inclusion criteria were clinically diagnosed case of epilepsy, patients who had been on at least one antiepileptic medication for 1 year or more prior to study, age of the patient's 13 years and both sexes. Exclusion criteria were patients with first-time seizures or newly diagnosed epilepsy and patients unwilling to participate in the study.

\section{Adherence Assessment:}

The Morisky Medication Adherence Scale-8 (MMAS-8) is a self-reported, medication-taking behavior scale used for assessment of adherence to anti-epilectic drugs. It consists of eight items focusing on past medication use patterns with a scoring scheme of "Yes" $=0$ and "No" $=1$ for the first seven items except item number five in which the values "Yes" and "No" were reversed and for the last item a five-point Likert response was used with options "never", "once in a while", "sometimes", "usually", and "always." In this Likert scale, values ranging from 0 to 1 were given at a specified interval of 0.25 with "0" given for "never" and " 1 " given for "always". The items were then summed to give a range of scores from low adherence to high adherence with a maximum score of 8 .

Adherent: If the MMAS - 8 score was $\leq 2$.

Non-adherent: If the MMAS - 8 score was $>2$.

\section{RESULTS}

Table I: Anti-epileptic drugs utilization pattern among epileptic patients

\begin{tabular}{lcc} 
Name of AED & Frequency & Percentage (\%) \\
Valproic acid & 77 & 30.4 \\
Carbamazepine & 59 & 23.3 \\
Phenytoin & 43 & 17.0 \\
Phenobarbital & 3 & 1.2 \\
Levetiracetam & 2 & 0.8 \\
Carbamazepine + Valproic acid & 18 & 7.1 \\
Valproic acid + Levetiracetam & 15 & 5.9 \\
Carbamazepine + Phenytoin & 13 & 5.1 \\
Valproic acid + Phenytoin & 8 & 3.2 \\
Valproic acid + Phenobarbital & 7 & 2.8 \\
Phenytoin + Levetiracetam & 5 & 2 \\
Carbamazepine + Phenobarbital & 3 & 1.2 \\
\hline
\end{tabular}

Among the 184 patients who were prescribed AED monotherapy, the most frequently prescribed AED was valproic acid $(30.4 \%)$ followed by carbamazapine $(23.3 \%)$. The most common AED dual therapy was carbamazepine with valproic acid (7.1\%). Majority (44\%) patients with focal epilepsy received carbamazepine while those with generalized epilepsy received valproic acid mostly (58\%) (Table I).

Table II : Results of the univariate analysis comparing patients with epilepsy who were adherent to their medications and those who were non-adherent $(\mathrm{n}=253)$

$\begin{array}{lllll}\text { Variable } & \begin{array}{l}\text { Number (\%) } \\ \text { Adherent } \\ (\mathbf{n = 9 8})\end{array} & \begin{array}{l}\text { Non-adherent } \\ (\mathbf{n}=\mathbf{1 5 5})\end{array} & \text { p-value } \\ \text { Sex } & \text { Male } & 54(34.8) & 101(65.2) & \\ & \text { Female } & 44(44.9) & 54(55.1) & \mathrm{p}=0.11 \\ \text { Age } & <18 \text { years } & 2(8.3) & 22(91.7) & \\ & \text { 18-30 years } & 26(29.9) & 61(70.1) & \\ & \text { 31-60 years } & 50(46.3) & 58(53.7) & \mathrm{p}<0.001 \\ & >60 \text { years } & 20(58.8) & 14(41.2) & \\ \text { Occupation } & \text { Student } & 14(35.0) & 26(65.0) & \\ & \text { Farmer } & 3(13.0) & 20(87.0) & \\ & \text { Housewife } & 37(51.4) & 35(48.6) & \mathrm{p}=0.019 \\ & \text { Service } & 21(29.1 .) & 51(70.9) & \\ & \text { Unemployed } & 24(52.2) & 22(47.8) & \end{array}$




\begin{tabular}{lllll} 
Education & Illiterate & $4(14.3)$ & $24(85.7)$ & \\
& Primary & $32(38.6)$ & $51(61.4)$ & \\
& Secondary & $32(36.4)$ & $56(63.6)$ & $\mathrm{p}=0.003$ \\
& Higher secondary & $17(56.6)$ & $13(43.4)$ & \\
& Graduate & $14(58.3)$ & $10(41.7)$ & \\
Residence & Urban & $35(40.7)$ & $51(59.3)$ & $\mathrm{p}=0.646$ \\
& Rural & $63(37.7)$ & $104(62.3)$ & \\
Duration of & & & & \\
illness & $<5$ years & $16(30.8)$ & $36(69.2)$ & $\mathrm{p}=0.043$ \\
& 5-10 years & $55(47.0)$ & $62(53.0)$ & \\
Types of & $>10$ years & $27(32.1)$ & $57(67.9)$ & \\
AED therapy & Monotherapy & $96(44.0)$ & $122(56.0)$ & $\mathrm{P}<0.001$ \\
& Polytherapy & $2(5.7)$ & $33(94.3)$ & \\
Seizure & & & & \\
control Status & Controlled & $70(82.4)$ & $15(17.6)$ & $\mathrm{P}<0.001$ \\
& Uncontrolled & $28(16.7)$ & $140(83.3)$ & \\
Monthly & & & & \\
cost, in Tk & (Mean \pm SD) & $488.98( \pm 276.45)$ & $683.23( \pm 565.33)$ & $\mathrm{p}=0.002$ \\
\hline
\end{tabular}

According to MMAS-8, 98(38.7\%) of the patients in this study were adherent and $155(61.3 \%)$ were non-adherent to AED therapy. Age, occupation, education, duration of illness, type of AED use, seizure control status and monthly expenditure were found to be significantly associated with adherence $(\mathrm{p}<0.05)$, while sex and dwelling place were not found to be significantly associated with adherence $(\mathrm{p}>0.05)$ (Table II).

Table III : Unadjusted Effects (Crude Odds Ratio) of categorical predictive variables on adherence to medication

\begin{tabular}{|c|c|c|c|c|}
\hline \multicolumn{2}{|c|}{$\begin{array}{l}\text { Categorical } \\
\text { predictor }\end{array}$} & $\begin{array}{l}\text { COR for } \\
\text { Adherence }\end{array}$ & $\begin{array}{l}95 \% \text { CI for } \\
\text { COR }\end{array}$ & p-value \\
\hline \multicolumn{5}{|l|}{ Sex } \\
\hline & Male vs. Female & 0.66 & $0.39-1.10$ & $\mathrm{p}=0.11$ \\
\hline \multirow[t]{3}{*}{ Age } & $<18$ yrs vs. $>60 y r s$ & 0.06 & $0.01-0.31$ & $\mathrm{p}<0.001$ \\
\hline & $18-30 \mathrm{yrs}$ vs. $>60 \mathrm{yrs}$ & 0.29 & $0.13-0.67$ & \\
\hline & $31-60 \mathrm{yrs}$ vs. $>60 \mathrm{yrs}$ & 0.60 & $0.28-1.32$ & \\
\hline \multicolumn{5}{|c|}{ Occupation } \\
\hline & Student vs. Unemployed & 0.15 & $0.21-0.47$ & $\mathrm{p}=0.019$ \\
\hline & Farmer vs. Unemployed & 0.28 & $0.37-0.69$ & \\
\hline & Housewife vs. Unemployed & 1.98 & $0.92-4.25$ & \\
\hline & Service vs. Unemployed & 0.19 & $0.25-0.58$ & \\
\hline \multicolumn{5}{|c|}{ Education } \\
\hline & Illiterate vs. Graduate & 0.13 & $0.04-0.44$ & $\mathrm{p}=0.003$ \\
\hline & Primary vs. Graduate & 0.30 & $0.15-0.73$ & \\
\hline & Secondary vs. Graduate & 0.46 & $0.23-0.91$ & \\
\hline & Higher secondary vs. Graduate & 0.72 & $0.49-1.34$ & \\
\hline \multicolumn{5}{|c|}{ Residence } \\
\hline & Urban vs. Rural & 1.13 & $0.66-1.93$ & $\mathrm{p}=0.646$ \\
\hline \multicolumn{5}{|c|}{ Duration of illness } \\
\hline & $<5$ years vs. $>10$ years & 2.94 & $2.45-5.98$ & $\mathrm{p}=0.043$ \\
\hline & $5-10$ years vs. $>10$ years & 1.87 & $1.04-3.3$ & \\
\hline \multicolumn{5}{|c|}{ Types of AED therapy } \\
\hline & Monotherapy vs. Polytherapy & 12.98 & $3.04-55.46$ & $\mathrm{p}<0.001$ \\
\hline \multicolumn{5}{|c|}{ Seizure control Status } \\
\hline & Uncontrolled vs. Controlled & 0.043 & $0.022-0.085$ & $\mathrm{p}<0.001$ \\
\hline
\end{tabular}

Tables III describe the unadjusted odds ratio of different predictive variables for adherence to AED. The odds of being adherent to AED among the patients aged 18-30yrs was decreased by $71 \%$ as compared to patient aged $>60$ years (COR: 0.29; 95\% CI: 0.13-0.67). Patients who were on single AED were 12.98 times more likely to be adherent to AED than those were on polytherapy.

Table IV : Adjusted Effects (Adjusted Odds Ratio) of categorical predictive variables on adherence to medication

\begin{tabular}{|c|c|c|c|c|}
\hline Categorical predictor & B & $\begin{array}{l}\text { AOR for } \\
\text { Adherence }\end{array}$ & $\begin{array}{l}95 \% \mathrm{CI} \\
\text { for AOR }\end{array}$ & $\begin{array}{c}\text { Test } \\
\text { statistics }\end{array}$ \\
\hline \multicolumn{5}{|l|}{ Sex } \\
\hline Male vs. Female & 0.77 & 2.15 & $0.59-7.81$ & $\mathrm{p}=0.243$ \\
\hline \multicolumn{5}{|l|}{ Age } \\
\hline$<18$ yrs vs. $>60 \mathrm{yrs}$ & -2.57 & 0.08 & 0.01-0.95 & $\mathrm{p}=0.045$ \\
\hline $18-30$ yrs vs. $>60 \mathrm{yrs}$ & -1.84 & 0.43 & $0.09-0.83$ & $\mathrm{p}=0.033$ \\
\hline $31-60$ yrs vs. $>60 \mathrm{yrs}$ & 0.37 & 1.48 & $0.32-6.39$ & $\mathrm{p}=0.641$ \\
\hline \multicolumn{5}{|l|}{ Occupation } \\
\hline Student vs. Unemployed & -0.38 & 0.06 & $0.09-0.28$ & $\mathrm{p}=0.02$ \\
\hline Farmer vs. Unemployed & -2.62 & 0.17 & $0.21-0.57$ & $\mathrm{p}=0.04$ \\
\hline Housewife vs. Unemployed & 0.19 & 1.21 & $0.15-9.72$ & $\mathrm{p}=0.87$ \\
\hline Service vs. Unemployed & -2.66 & 0.07 & $0.12-0.39$ & $\mathrm{p}=0.01$ \\
\hline \multicolumn{5}{|l|}{ Education } \\
\hline Illiterate vs. Graduate & -1.31 & 0.09 & $0.01-0.43$ & $\mathrm{p}=0.003$ \\
\hline Primary vs. Graduate & -1.99 & 0.14 & $0.03-0.64$ & $\mathrm{p}=0.012$ \\
\hline Secondary vs. Graduate & -1.54 & 0.21 & $0.06-0.74$ & $\mathrm{p}=0.015$ \\
\hline Higher secondary vs. Graduate & 0.57 & 0.49 & $0.27-1.19$ & $\mathrm{P}=0.321$ \\
\hline \multicolumn{5}{|l|}{ Residence } \\
\hline Urban vs. Rural & -1.06 & 0.35 & $0.12-1.01$ & $\mathrm{p}=0.052$ \\
\hline \multicolumn{5}{|l|}{ Duration of illness } \\
\hline$<5$ years vs. $>10$ years & 1.87 & 6.49 & $1.95-21.56$ & $\mathrm{p}=0.002$ \\
\hline $5-10$ years vs. $>10$ years & 1.17 & 3.25 & $1.18-8.87$ & $\mathrm{p}=0.022$ \\
\hline \multicolumn{5}{|l|}{ Types of AED therapy } \\
\hline Monotherapy vs. Polytherapy & 2.10 & 8.15 & $1.43-46.2$ & $\mathrm{p}=0.018$ \\
\hline \multicolumn{5}{|l|}{ Seizure control Status } \\
\hline Uncontrolled vs. Controlled & -4.27 & 0.02 & $0.004-0.05$ & $\mathrm{p}<0.001$ \\
\hline
\end{tabular}

A binary logistic regression was performed to ascertain the effect of different categorical predictive variables on the likelihood that patient was adhering to AED or not. The model was statistically significant $\left(\chi^{2}=167.95, \mathrm{p}<.001\right)$ and explains $65.1 \%$ (Nagelkerke $\mathrm{R}^{2}$ ) of the variance in treatment adherence and correctly classifies $85.4 \%$ cases.

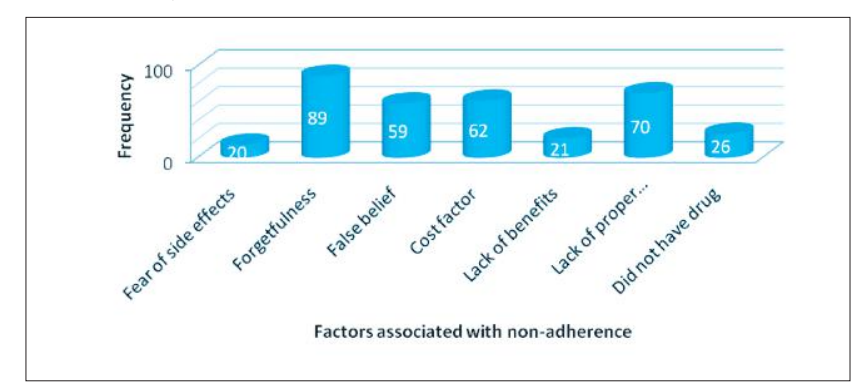

Figure 1 : Factors associated with non-adherence to AED 
Fig 1 shows the factors associated with non-adherence to AED. Forgetfulness was the most common factor for non-adherence (35\%), followed by lack of counseling $(27.67 \%)$, cost of drug $(24.5 \%)$, false belief $(23 \%)$, drug unavailability $(10.2 \%)$, lack of benefit (8.3\%) and fear of side effects (7.9\%).

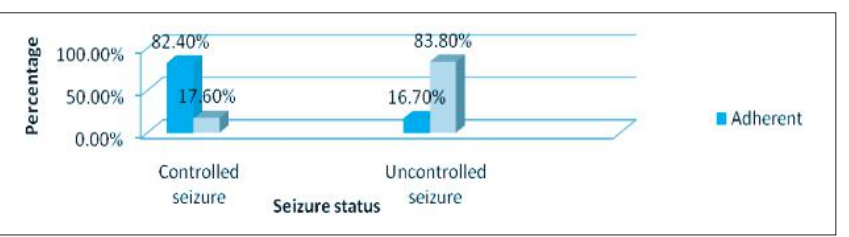

Figure 2 : Relation of seizure status with AED adherence

Figure 2 shows patients with non-adherent to AEDS had significantly more seizures thanthose with adhere.

\section{DISCUSSION}

Adherence to medication is regarded as a major challenge in developing countries as a result of low income, illiteracy and ignorance. Although Non adherence is considered to be one of the major causes of non-responsiveness to AED therapy, this has not been studied extensively in Bangladesh. To fill this gap, we assessed the extent of AED adherence, as well as the factors influencing AED adherence among Patients with Epilepsy at $\mathrm{CMCH}$.

Adherence to AEDs can be measured in several ways including self-report, pharmacy refill reports, electronic monitoring, and direct observation and by serum level drug concentration measuring. Only $38.7 \%$ of these study subjects are adhering to AED therapy. This showed that the non-adherence to AED therapy among epilepsy patients is still high. In 2003, WHO reported that the prevalence of adherence to AEDs in developing countries ranged between $20 \%$ and $80 \%{ }^{7}$. Hence, our finding showed that the issue of non-adherence remains to be important for the past 15 years.

The rate of adherence to AEDs observed in the present study is in line with the study found in Brazil (33.8\%), Malaysia $(35.9 \%)$ UK $(41 \%)^{8-10}$. However, it was less than that of Iran (75\%), USA (71\%), China (51.9\%), Saudi Arabia (62.7\%) ${ }^{11-}$ $14,17,22$. These variations in rate of adherence between different studies may reflect the differences in patient attitude toward the prescribed drug due to different cultures, beliefs, education, and physician approach to the patient with epilepsy or the degree of medical and parental support.

Many studies showed that age was related to adherence. In this study, non-adherence was more common among younger patients. Study carried out in Brazil and in Malaysia showed same type of result ${ }^{8,9}$. A observation was reported earlier in which a higher adherence level to AED therapy was associated with elderly patients ${ }^{15}$. The possible explanation to this observation is that younger patients are pre-occupied with an active social life, academic studies or jobs causing them to sometimes forget to take their medication, and they may also think that they are healthier and do not require any treatment.
Older people might also have more concern about their health than younger patients, so that older patients' non-compliance is non-intentional in most cases. As a result, if they can get the necessary help from healthcare providers or family members, they may be more likely to be compliant with therapies.

Regarding the educational level, background of majority of the study participants was found to be primary and secondary school level but illiterate and graduate level of PWE also found. This finding demonstrates that epilepsy can occur equally in less educated and highly educated individuals as educational level have no role in incidence of epilepsy among people.

But result shows that education may have some role in adherence with epilepsy and patients with less education have more chance of non-adhere than the educated patients. This is probably because educated patients had more and appropriate information on the disease and importance of adherence. Furthermore because of their education level, they can interact well with health care givers and ask relevant questions.

The findings showed that duration of illness were found to have statistically significant association with adherence of patients. The multivariable logistic regression analysis showed the odds of adherent to AED among patients who had epilepsy for less < 5 years was increased by 6.49 times as compared to those had duration of epilepsy for 5-10 years but latter group was 3.25 times more adhere than those had $>10$ years history. This reported that patients who were taking AEDs for longer duration were poorly complaints to their medications because of long term therapy, experiencing side effects of medication for long periods and because of financial burden on the patient's life.

Most patients with epilepsy respond to one of the first- line AEDs; second-line agents may be useful in patients who do not respond to one or a combination of the first- line agents. In the present study, Valproic acid (30.4\%) was found to be the most frequently prescribed drug as monotherapy followed by carbamazepine (23.3\%). This is in line with a study in Saudi Arabia which showed Valproic acid was the most common prescribed drug to control epilepsy (59.6\%) followed by carbamazepine $(12.8 \%)^{14}$.

Monotherapy has been the gold standard for epilepsy treatment. The present study also revealed that monotherapy (72.7\%) was used as the preferred treatment modality. This finding is in line with the findings in Saudi Arabia (76.6\%), Pakistan (77.5\%) and UK (78.8 \%) but study done in China and Cambodia found $62.4 \%$ and $60 \%$ PWE on monotherapy respectively ${ }^{14,16,17,13,18}$. Study done in Dhaka, Bangladesh found $67 \%$ patients on monotherapy ${ }^{19}$. Patients on monotherapy were 8.15 times more adhere than those take polytherapy.

By contrast, adherence of the patients to their medication didn't show significant association with place of residence. This result is in line with the findings in Uk, China, Nigeria and in Iraq ${ }^{10,13,20,21}$. The effect of gender as an important contributing 
factor affecting the medication adherence was studied. Gender was shown not to be statistically significantly associated with adherence to anticonvulsants. But, Study done in Brazil found Females were more adherent than male as because Female are more accepting of the diagnosis, while male tend to prioritize work and delay seeking medical care to avoid unemployment. Treatment non-adherence probability was lower among patients with seizure control. Adherence was shown to positively associate with seizure control in the present and others study ${ }^{8,22,23}$. A study by Hovinga et. al compared two epilepsy patient groups (Adherent vs non adherent) also found nonadherence to be associated with reduced seizure control ${ }^{12}$. Jones et al showed that low treatment adherence is strongly associated with uncontrolled seizures among epilepsy patients ${ }^{10}$.

As we are living in a developing country, patients have a very low monthly income to afford antiepileptic medications. This might have contributed to low level of adherence in our set up. In relation to financial factors, this study confirmed that there is a strong positive correlation between patient's monthly cost of AED and level of adherence. This study investigated the top reasons for non-adherence to AED medications and found that forgetfulness was the most common cause of nonadherence.

\section{CONCLUSION}

The present study on AED adherence shows that the rate of non-adherence to AED was found in about two thirds of patients. Seizure control was achieved only in one third of the patients. Adherence to AED was found to have a significant association with seizure control status. The finding that seizure control is correlated with non-adherence indicates that therapy to promote adherence to medication could be an important part of the treatment strategy provided by a specialist clinic.

\section{RECOMMENDATIONS}

The present study was carried out in a tertiary healthcare setting, which made it difficult to extrapolate findings to the general population so further studies be conducted to measure adherence in a more varied population in order to better address the issue of AED adherence. Sample size of this study was relatively small therefore recommend that future research studies with a larger sample.

In this study, we found that non-adherence to medication is common in epilepsy. An approach which focuses on the choice and dose of antiepileptic will have limited success if the prescribed treatment is not adhered to. All health care professionals have to find out all factors connected to each patient's adherence to AEDs and try to modify them in an individualized form and should spend sufficient time in educating the patients to improve the adherence level.

\section{DISCLOSURE}

All the authors declare no competing interest. 


\section{REFERENCES}

1. Fisher RS, Acevedo C, Arzimanoglou A, BogaczA, Cross JH,Elger C, Engel JJJr, Lars Forsgren, French JA, Glynn M, Hesdorffer DC, Lee B, Mathern G, Moshe SL, Perucca E,. Scheffer IE, Tomson T, Watanabe M, and Wiebe S. A practical clinical definition of epilepsy.Epilepsia,2014; 55(4):475-482.

2. WHO. Epilepsy in the WHO African region: Bridging the gap. The Global Campaign against Epilepsy.2004.

3. WHO. Epilepsy: epidemiology, aetiology and prognosis. WHO fact sheet. Available at: http://www.who.int/inf-fs/en/fact165.html.2001.

4. Searo Report. How Common is Epilepsy in South-East Asia? Some facts and figures on Epilepsy.Avaialable at: http://tinyurl.com/ngcl4bd.

5. Banerjee PN, Filippi D, Hauser WA. The descriptive epidemiology of epilepsy - A review.E R.2009;85(1): 31-45.

6. WHO. Epilepsy in the WHO African region: Bridging the gap. The Global Campaign against Epilepsy. 2004.

7. WHO. Adherence to Long-term Therapies: Evidence For Action. Geneva: World Health Organization. 2003.

8. Carla Maria Maluf Ferrari a, Regina Ma' rcia Cardoso de Sousa ,Luiz H.M. Castro. Factors associated with treatment non-adherence in patients with epilepsy in Brazil. Seizure.2013; 22 384-389.

9. XC Tan B Pharm (Hons), M Makmor-BakryM Pharm (Clin) PhD, CL Lau BSc (Pharm) M ClinPharm,FWTajarudinMPharm, AA Raymond MD FRCP.Factors affecting adherence to antiepileptic drugs therapy in Malaysia.Neurology Asia.2015; 20(3) : $235-241$.

10. Jones RM, Butler JA, Thomas VA, Peveler RC, PrevettM.Adherence to treatment in patients with epilepsy: Associations with seizure contro and illness beliefs.2006; SJ 15(7): 504-508.

11. Asadi-Pooya, A.A..Drug compliance of children and adolescents with epilepsy. Seizure2005:14, 393-395.

12. Hovinga CA, Asato MR, Manjunath R, Wheless JW, Phelps SJ, Sheth RD et al. Association of non-adherence to antiepileptic drugs and seizures, quality of life, and productivity: Survey of patients with epilepsy and physicians. E \& B.2008; 13(2): 316-322.

13. Liu J, Liu Z, Ding H, Yang X. Adherence to treatment and influencing factors in a sample of Chinese epilepsy patients.ED.2013; 15(3): 289-294. 43

14. Gabr WM, Shams ME. Adherence to medication among outpatient adolescents with epilepsy.SPJ.2015; 23 (1): 33-40.

15. Buck D, Jacoby A, Baker GA, Chadwick DW. Factors influencing compliance with antiepileptic drug regimes.Seizure.1997; 6:87-93.

16. Faizan M, Sumbul S. Drug Utilization Evaluation of Antiepileptics in Three Selected Multidisciplinary Teaching Hospitals of Pakistan.IJPPS.2014; 6(5): 59-66.

17. Morgan CL, Buchan S, Kerr MP. The outcome of initiation of antiepileptic drug monotherapy in primary care: a UK database survey. BJGP.2004; 54(507): 781-783.

18. Bhalla D, Chea K, Hun C, Chan V, Huc P, Chan S et al. Epilepsy in Cambodia-treatment aspects and policy implications: a population-based representative survey.2013; PS 8(9): 1-9.

19. Habib M, Khan SU, Hoque, MA, Mondal MB, Hasan AH, Chowdhury RN, Haque B, Rahman KM et al. Antiepileptic drug utilization in Bangladesh: experience from Dhaka Medical College Hospital. BMCR.2013; 6: 473.42

20. Johnbull OS, Farounbi B, Adeleye AO, OgunrinO.Evaluation of Factors Influencing Medication Adherence in Patients with Epilepsy in Rural Communities of Kaduna State, Nigeria. N \& M.2011; 2: 2 99-305.

21. Ibrihemkhasro, Salem Rahma.Drug Compliance In Epileptic Children In SulaymaniGovernate .Drug Compliance In Epileptic Children.2010; 9(2)

22. Nakhutina L, Gonzalez JS, Margolis SA, Spada A, Grant A. Adherence to antiepileptic drugs and beliefs about medication among predominantly ethnic minority patients with epilepsy.E\& B.2011; 22(3): 584-586.

23. Egenasi C, Steinberg WJ, Raubenheimer JE. Beliefs about medication, medication adherence and seizure control among adult epilepsy patients in Kimberley, South Africa. SAFP.2015;57(5): 326-332. 